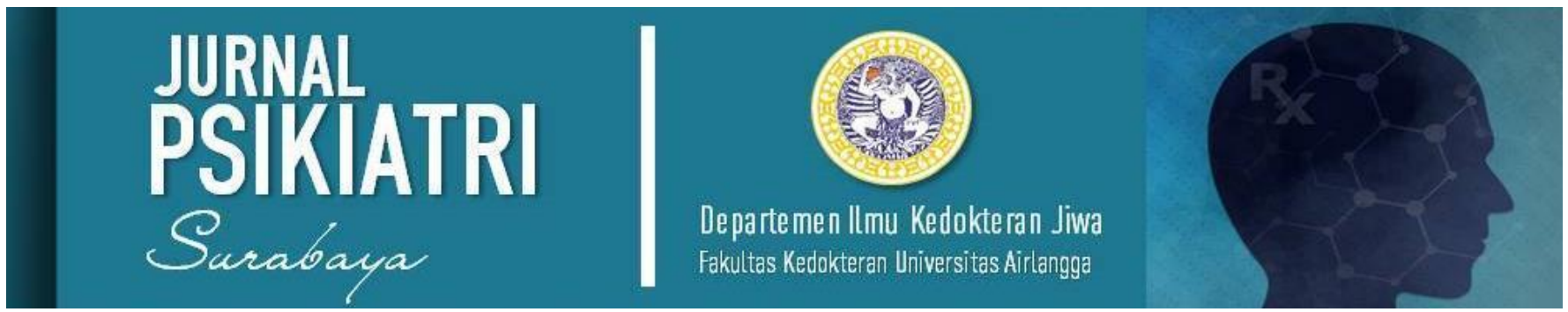

Literature Review

\title{
Psychoanalytic Listening: between unconscious and conscious
}

\section{Limas Sutanto ${ }^{1}$}

${ }^{1}$ Department of Psychiatry, Faculty of Medicine, Universitas Brawijaya, Malang, Indonesia

\section{OPEN \\ ACCESS}

\section{ARTICLE INFO}

Received: November 26, 2020 Revised: December 18, 2020 Accepted: December 20, 2020 Published: May 31, 2021

*) Corresponding author: E-mail:

limas.sutanto@gmail.com

$$
\begin{aligned}
& \text { Keywords: } \\
& \text { psychoanalytic } \\
& \text { listening } \\
& \text { unconscious } \\
& \text { apprehension } \\
& \text { conscious } \\
& \text { comprehension }
\end{aligned}
$$

This is an open access article under the CC BY-SA license (https://creativecommons.org/lic enses/by-sa/4.0/)

Abstract
Psychoanalytic listening can be deployed for enhancing the quality of clinical
psychiatric practice. As a clinical skill, it should be teachable throughout the years
of psychiatric residency. Nevertheless, the teaching of such important faculty is
difficult due to the scarcity of a systematic, relatively structured model that can be
used as an underpinning of learning that capability. This article is aimed at fulfilling
a part of that lack of teaching methodology. The model offered in this article
describes psychoanalytic listening as a mental process initiated by the therapist,
which then goes through the patient too, which involves a continuing oscillation of
unconscious apprehension and conscious comprehension. This rhythmic proceeding
of affectively experiencing and rationally considering will expectedly bring about a
mutual understanding between patient and therapist which then facilitates further
clinical enterprises.

Psychoanalytic listening can be deployed for enhancing the quality of clinical psychiatric practice. As a clinical skill, it should be teachable throughout the years of psychiatic residency. Nevertheless, the teaching of such important faculty is difficult due to the scarcity of a systematic, relatively structured model that can be used as an underpinning of learning that capability. This article is aimed at fulfilling a part of that lack of teaching methodology. The model offered in this article describes psychoanalytic listening as a mental process initiated by the therapist, which then goes through the patient too, which involves a continuing oscillation of unconscious apprehension and conscious comprehension. This rhythmic proceeding of affectively experiencing and rationally considering will expectedly bring about a clinical enterprises.

Cite this as: Sutanto, L. "Psychoanalytic Listening: between unconscious and conscious". Jurnal Psikiatri Surabaya, vol. 10, no. 1, pp.13-19, 2021, doi: 10.20473/jps.v10i1.23429. 


\section{INTRODUCTION}

The term "listening" in this article means "psychoanalytic listening", a kind of hearing to the patient in a clinical situation which is attributed to the deployment of Freud's "evenly hovering attention" [1]. It would be reasonable to implicate that way of listening in clinical psychiatric setting because in that field there are many patients with unconscious psychopathological problems that require to be resolved through "unconscious-to-unconscious" communication with psychiatrist. Beginning from this point, the author tries to synthesize clinical and academic informations pertaining to that topic, sometimes combined with his own clinical experiences as a psychoanalytically, psyhotherapeutically oriented practicing psychiatrist, with the main purpose of elaborating a relatively structured understanding about how psychoanalytic listening can be practiced and taught as a clinical skill.

Listening is a challenging clinical skill for practicing psychiatrists at large because of the fact that their work field - clinical psychiatry - is being an intersection between two different epistemological areas, each of which is a unique way of how to reach knowing and understanding in that field: the deductive and the hermeneutical. Listening is much more in the hermeneutical than in the deductive area. Amidst the great propensity of the mainstream psychiatry to position itself as a part of the medical sciences-thus it should be more deductive than hermeneutical-listening tends to not so seriously be considered as an important clinical psychiatric skill. Listening, which is more accounted for the hermeneuticists than to the deductivists, is apt to be categorized as a psychological skill for psychotherapists and clinical psychologists than for psychiatrists [2].

Nonetheless, the hermeneutical element of clinical psychiatry could never be totally omitted by practicing psychiatrists. This is due to the fact that dealing with patients suffering from mental problems means relating and attuning to their subjective, idiosyncratic experience, which in each of the individuals demands to be empathically understood with a very minimum degree of generalization. In this respect, listening emerges as a very important even essential clinical skill which can be deployed by psychiatrists in order to enhance the quality of their services.
In addition to the lack of serious consideration concerning listening as an important clinical skill in psychiatric practice, learning such skill is inclined to be difficult because of the broad spectrum of various ways of listening. Salman Akhtar (2013) describes the diversity of the focus among the respective proponents of different methods of listening. The variousness is being reflected by the reality that along the history of psychoanalysis, the topic of listening has never been discussed as a single entity; at least it can be mentioned four categories of listening that evolve throughout the psychoanalytic discourse: objective listening, subjective listening, empathic listening, and intersubjective listening. This categorization mirrors the complex nature of listening, hence it can only be mastered through many experiences of practicing it in clinical field. In this perspective, teaching listening skill requires a relatively clear roadmap of the learning process - a requirement that hasn't been adequately fulfilled.

Another hindrance to the positioning of listening as an important clinical skill in psychiatric practice is the fact that some of the psychiatric patients demonstrate mutism as one of their psychopathological symptoms. One of the questions frequently asked concerning the universality of listening in psychiatric practice is about the seemingly ironical fate of listening in front of the service for such patients with a reluctance to talk. For instance, some of psychotic individuals, because of their persecutory auditory hallucination, decide to not to talk anymore for the sake of evading the fantasied danger of talking. Is listening abiding necessary in such clinical context?

Regarding this issue, Freud exhorts that listening is really not restricted to the patient's spoken words. It also includes paying attention to his silences, and to the nonverbal cues he offers [4], [3]. Listening is not just simply an act of hearing but an attitude that is deeply ingrained in the psychiatrist's mind. Thus, it will be unconsciously reflected by the whole nonverbal presentation of the physician. A listening-helper will unwittingly resonate a body language that attracts people to communicate at large, not confined in merely verbal communication. On the other hand, an internalized attitude of listening in the psychiatrist as a person will inspire himself to create innovative initiatives for communicating beyond talking. The listening attitude of the clinician is a sort of receiving patients, or "getting them", resonating 
with them implicitly, or nonverbally. Biologically, this is a resonance with or attunement to others through the mirror neuron system [5].

\section{Clinical illustrations that reflect the importance of listening}

Following are two short illustrations that show the importance of listening. Sometimes listening is an unreplaceable clinical tool for effectively helping patient; even "the most efficacious medication"-whether such kind of drug be available - is unable to substitute its role. It would frequently be unable for the clinicians to help the patient to dissipate his suicidal thought by medication. It also very difficult for the psychiatrists to overcome the patient's mutism just merely through prescribing drug for him. Only through listening, the clinicians gain access to the meaning of those symptoms, thus they are capable of responding appropriately to that meaning.

\section{Illustration 1}

A 21-year-old female patient has been complaining about her willingness of committing suicide since more than two years ago. She has ever met eight different psychiatrists within that period. Each time she was engaging in a therapeutic relationship with one of the psychiatrists, she verbally expressed her suicide ideation to the psychiatrist. What she always got in return following such communication was a sort of immediate advice from the therapist that stressed the importance of maintaining life as a kind of moral obligation that attached to every person's existence. Soon after that, she decided to terminate the therapy, and then she moved to another psychiatrist for seeking other therapeutic experience that deemed more appropriate for her. Just right at her meeting with the eighth psychiatrist she obtained what she needed, that was a need to be listened patiently, basically without any comment at all. She just merely wanted to be treated by a therapist who functioned himself as being a large container for accepting every verbal expression from her, especially pertaining to her suicidal thoughts. She described that she just yearned for being facilitated to elaborate her subjective experience about her inclination to suicide. She felt that this was really a very horrific topic for her, but she had it, and hence she needed to be accompanied by a nonjudgmental, truly listening therapist to work through that kind of experience. At the end of her session with such listening psychiatrist, she earned a convincing attitude that she will not to ruminate the suicide ideation anymore.

\section{Illustration 2}

A former mute patient submitted himself since the first minutes of her encounter with the psychiatrist with an attitude of destructing contact between them. The patient sat with an awkward, drooping posture, fidgetingly clapping her palms on the table in front of her. However, the psychiatrist initiated a non-verbal plea to the patient for expressing himself via writing or drawing on a piece of paper. He quietly presented some pieces of paper and a pencil to the patient. Fortunately, the patient met his physician's initiative with a gradual increase of enthusiasm. She asked for more papers to write and draw. And the psychiatrist continued responding to her nonverbally; in addition to offering more papers, he conveyed other responses to the patient through writing and drawing as well.

Apparently, this kind of slightly prolonged nonverbal communication made the patient imbued with an experience of safety and impregnated with a feeling of being understood. Suddenly she broke her mutism when she spontaneously uttering a short sentence: "I am not confusing anymore!" This occurrence bore the impression that the attuned nonverbal interaction with the therapist facilitated the patient to clarify some of her previously unsaid thoughts, therefore ameliorating her befuddlement.

That was the beginning of a recovered verbal communication. Since that moment, the patient communicated with the helper more verbally than bodily. And the psychiatrist continued to listen to the patient attentively. He also persisted in observing the patient's bodily expressions unobtrusively.

Hence, listening is deserved to be considered as an important, even essential, clinical skill for enhancing the quality of psychiatric practice. The problem remains how to create a relatively structured way of listening, so it can be teach properly during years of psychiatric training program. This paper is aimed at resolving that problem.

\section{DICUSSION}

Two of the outstanding names in psychoanalysis, Sigmund Freud and Wifred Bion, both of them cannot be separated from any serious psychoanalytic discussion concerning listening. 
Freud's suggestion is very illustrious: for the analysts to be able to connect their unconscious to the patient's unconscious, they need to listen the patient's utterances in an evenly hovering fashion [1]. Bion made another notion on listening: the purest of listening is to listen without memory or desire [6]. The British object relations theorist don't explicitly claim that his opinion about how to perform listening is a descriptive elucidation of Freud's 'evenly hovering listening'. Nonetheless, both of the notions have a similar goal of connecting the patient's unconscious with the analyst's unconscious. According to Freud, in order to activate their unconscious mind, analysts require to articulate an evenly hovering attentiveness. In Bion's view, enhancing the function of unconscious mind can be accomplished by practicing an attitude of letting go. Both Freud's attending hoveringly and Bion's listening without memory or desire are nonverbal phenomena emanating from the unconscious right brain, and they are directed to the patient's unconscious. Therefore, both Freud's suggestion and Bion's account on listening can be utilized as being two decipherments which are complementary for each other. Listening would be consummated in an "evenly hovering, without memory or desire modus operandi“.

Such distinctive way of listening creates a phenomenological space containing the immediacy of the patient's words. In this way analysts are being refined from any nuisance comes out from their own thought and feeling. What needs to be prosecuted by analysts is just only facilitating the patient to talk and talk, to expand his wording of experience that evolves into a broader verbal revealing, without the analysts adding any idea or feeling from the outside.

Due to its 'evenly hovering' and 'without memory or desire' characters - this unfocused posture opens a large landscape ahead - that kind of listening also provides therapists the opportunity to observe the patient's nonverbal expressions; thus, listening to the verbal and the nonverbal as well. In his classical writing about psychoanalytic listening, psychoanalyst Theodor Reik describes the listening enterprise as "a listening with the third ear". He borrows the term "the third ear" from a passage in Nietzsche's Beyond Good and Evil that discusses the ability to appreciate the musicality of language [7]. What the sensitive therapist hears is not merely the patient's wording but also the nonverbal messages delivered through the prosody of the verbalization. Grasping hunches emitted from the musicality of the patient's language is a sort of unconscious right brain endeavor of therapists which is directed to the patient's unconscious; hence, realizing an unconscious to unconscious listening. Reik suggests that "listening with the third ear" needs to be performed by postponing logical interpretation by therapists until the arrival of its proper timing. It also means that therapists need to suspend their reasoning in order to give way for the emotional undertones of the patient's associations to become clearly audible and distinct as if amplified by a microphone [8].

The unconscious nature of psychoanalytic listening is also discussed by Gabriel Sapisochin. He considers listening as being a transference-countertransference based understanding that occurs when the patient's "psychic gestures"-his archaic relational experiences with primal objects registered in an image-based form - are being enacted mostly through verbalization within the context of his current therapeutic relationship with his therapist. Thus, listening is undertaken intensively during the patient verbally enacting his psychic gestures-an analytic listening through the medium of enactment. Really, although this fashion of listening involves attending to the verbal aspect of the patient's experience, but really it also entails engaging his nonverbal expressions [9].

The central role of listening in developing patient-therapist alliance which then facilitates understanding between the two parties is elaborated by James Fosshage. For the relational self psychological psychoanalyst, listening is a matter of how the therapist experiences the patient. He puts forward the phrase "the analyst's experience of the analysand", instead of the term countertransference, which for him is more fully capturing the complexity of the analyst's involvement and correctly placing it as a central guide for inquiry and intervention. The analyst's moment-to-moment experience of the patient is shaped not simply by the patient, but also by the analyst's listening perspective. There are two listening perspectives, i.e. the subject-centered listening perspective (primarily influenced by the psychoanalytic self psychology), and the other-centered listening perspective (largely given great importance in object-relations and interpersonal approaches). With the former listening perspective the analyst is able to experientially resonate with the patient's affect, and to experience from within the patient's point of view. From the later listening perspective the analyst can experience the patient from the vantage point of the other 
JPS. Volume 10 No 1. May 2021 / Psychoanalytic Listening: between unconscious and conscious

person to whom the patient has been related with. Fosshage proposes that the analyst's listening from within and from without, oscillating in a background-foreground configuration, illuminating the patient's experience of self and of self in relation to others [10].In performing psychoanalytic listening, clinicians deploy every aspect of their existence-their personality, creativity, and 
knowledge. Fred Pine elucidates this perspective through relating listening to an open-minded multimodel approach to theories of mind, and to an open-ended multifactor approach to theories of technique, that have always been implicitly present in psychoanalytic practice. Communication in the psychoanalytic situation takes place via multiple channels and in diverse ways: through words, affects and behavior, as well as through personal presence that set a mood, that have an impact and induce various states or evoke certain role reponses in the analyst; and also by means of transference in its original and expanded ("total situation ") senses, and potentially over countertransference responses. The communication also occurs in reaction to the analyst's neutrality and relative anonymity, and in reaction to the analyst's cues, self revelations and values which, at least to some degree, ooze from every pore. So, for communicating psychoanalytically, an open-ended multi-model, multifactor deportment is a necessity. The entire process of listening is essentially a creative endeavor with a strong relatedness to knowledge. The multi-model theories of mind and the multi-factor theories of technique present a vast array of that knowledge. And the most possible attitude that opens ways to creatively use that knowledge is an attitude of "it just might be", a flexibility and a humbleness with a maximum receptivity to the patient's experiences [11].

Those previous elaborations of the richness and complexity of listening experience demand to be followed by an effort to provide a systematic and relatively structured framework of psychoanalytic listening, so psychoanalytic listening can be taught and be repeated according to a relatively structured conceptual underpinning. Regarding this requisite, Gavin Ivey recommends a "listening-formulating model for conducting psychoanalytic psychotherapy". He expects that the model will be useful for teaching on how to listen psychoanalytically [12]. In constructing his model, Ivey integrates Sigmund Freud's proposition on evenly suspended attention [1], Nina Coltart's idea about bare attention [13], the concept of free-floating and poised attention by Theodor Reik [14], and Wilfred Bion's notion concerning reverie [15]. The model is basically pertaining to how unconscious and conscious mental processes involve in a rhythmic cooperative undertaking of realizing an intersubjective communication. Initially the part of the mental processes that works in a person open to communicating with another person is his humble attitude for putting aside his knowledge, desire, and expectation; thus, he takes a stance of "not knowing “. This openminded unknowingness creates an optimal opportunity for the unconscious to undertake the task of apprehension, i.e. spreading a broad landscape for receiving any data, just merely for the purpose of containing all of the materials communicated by the other person without discriminating, ordering, analyzing, or sorting them for whatever reason. This is a real act of listening which essentially has an unconscious characteristic and involves a part played by an attitude of being reverent to the other.

The large mental landscape and extensive affective opennes that have been created through the aforementioned apprehension convey a conducive atmosphere then for a conscious, rational comprehension to conduct its task appropriately, managing a deliberation upon the materials that have been contained before, and then proposes a tentative thought which hopefully will be suitable for the other person. Then the other person will propound his own response to that tentative thought, and the processes of unconscious apprehension and conscious comprehension will cyclically continue. Hence, the mental process always oscillating between unconscious and conscious, between listening/containing and deliberating/proposing, between apprehending and comprehending, between feeling and thinking, and between affectively experiencing and rationally considering. This cyclical mental process will underlie an enduring course of communicative actions towards mutual understanding. In the perspective of a psychotherapeutic encounter, the proceeding is initiated by the therapist, which then goes through the patient too.

Through that particular kind of clinical encounter with a listening-therapist, patients depicting their own subjective experiences as large as possible, so those experiences which are initially unspeakable become speakable, and they together with their analyst grasp a more complete picture of their experiences. This is a process of expanding and clarifying experiences, and at the same time illuminating and understanding them [2]. That is an ongoing unfolding of the unconscious to become conscious, to understand those that formerly couldn't be understood, to re-own experiences that were disowned from the patient's personality in the past, and to 
re-integrate experiences which were previously fragmented.

The broad apperception of the patient's experiences will result in the arising of a challenge to create a novel future, a new way of being and relating, which emerges from the imagination embedded in such large picture of comprehensible experiences. Analysts require themselves to be sensitive to that imagination, accordingly they would be capable of encouraging the patient to realize his or her own imagination into a new way of being and relating.

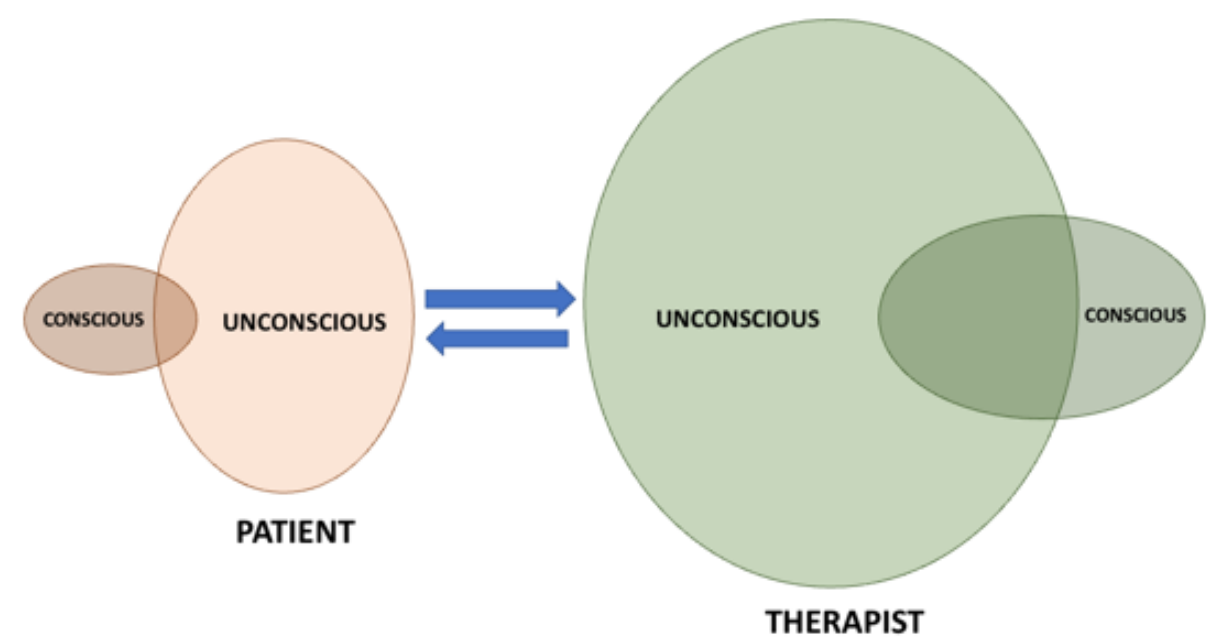

DIAGRAM 1. APPREHENSION. In this initial phase of psychoanalytic listerine, the therapist opens a broad landscape of his unconscious through applying an evenly hovering attention for the purpose of receiving whatever materials communicated by the patient's unconscious.

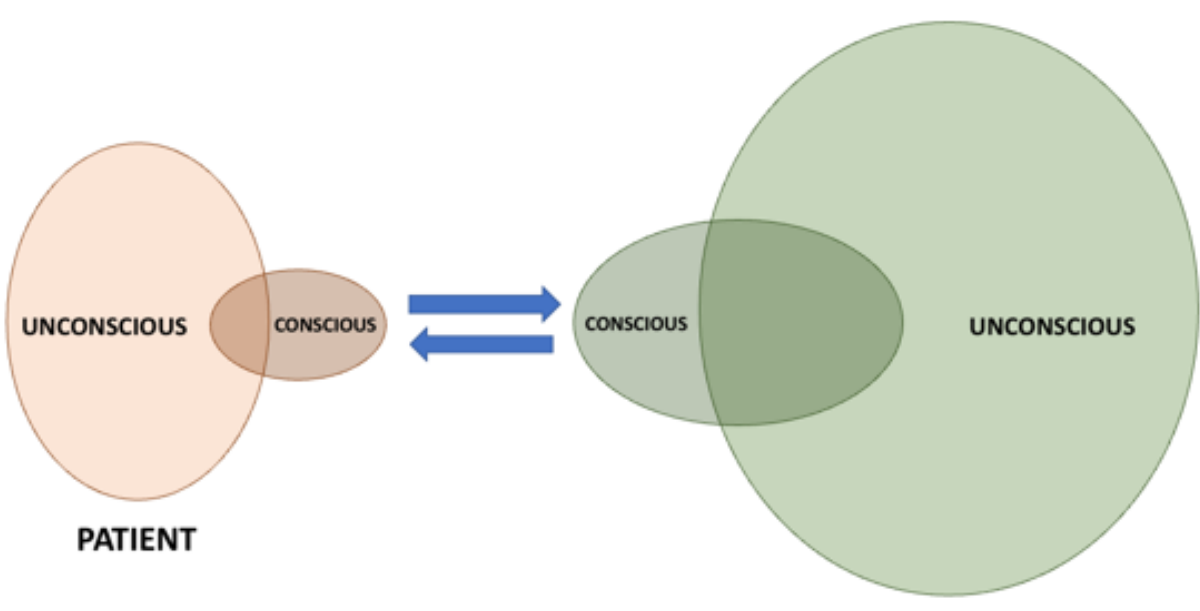

THERAPIST

DIAGAAM 2. COMPREMENSION. In this subsequent phase of psychounalytic listening, the therapist consciously discriminates, onders, analyzes, and classifies the patient's unconscious materials and then proposes a thought that expectedly suitable for the parient.

\section{CONCLUSION}

Communicating intersubjectively is not merely an act of changing the other, but also a giving of oneself to bechanged by another person. An attitude of humbleness and an open minded unknowingness that open a broad landscape of unconscious receptiveness - i.e. the essence of listening-will be the initial part of the cyclical mental process of intersubjective communicating. The subsequent part of this mental endeavor is characterized by a conscious 
undertaking of comprehension. The overall of conducting psychoanalytical communication is managing a continuing cycle of engagement that rhythmically involves unconscious and conscious mental processes towards mutual understanding.

\section{REFERENCES}

[1] S. Freud, Recommendations to Physicians Practicing Psychoanalysis In J. Strachey (Ed. \& Trans.), The Standard Edition of the Complete Psychological Works of Sigmund Freud, vol. 12. London: Hogarth Press, pp. 109-121, 1912.

[2] F. Summers, The Psychoanalytic Vision: The Experiencing Subject, Transcendence, and the Therapeutic Process. New York: Routledge, pp. 516, 2013.

[3] S. Akhtar, Psychoanalytic Listening: Methods, Limits, and Innovations. London: Karnac Books, pp. 1-15, 2013.

[4] S. Freud, "Introductory Lectures on Psychoanalysis. In J. Strachey (Ed. \& Trans.),'The Standard Edition of the Complete Psychological Works of Sigmund Freud. London: Hogarth Press, vol. 17, pp. 7-124, 1917.

[5] G. Westland, Verbal and Non-verbal Communication

in Psychotherapy. New York: W. W. Norton \& Company, pp. 92-95, 2015.

[6] W. R. Bion, Attention and Interpretation. London:
Travistock, pp. 41-54, 1970.

[7] F. Nietzsche, Beyond Good and Evil. New York: NY: Penguin, pp. 144-145, 1973. (Original work published 1886).

[8] K. Arnold, "Reik's Theory of Psychoanalytic Listening," Psychoanal. Psychol., vol. 23, no. 4, pp. 754-765, 2006.

[9] G. Sapisochin, "Enactment: Listening to Psychic Gestures," Int. J. Psychoanal., 2019, doi: 10.1080/00207578.2019.1600372.

[10] J. L. Fosshage, "Countertransference as the Analyst's Experience of the Analysand: Influence of Listening Perspective," Psychoanal. Psychol., vol. 12, no. 3, pp. 375-391, 1995.

[11] F. Pine, "Listening and Speaking Psychoanalytically_With What in Mind?," Int. J. Psychoanal., vol. 82, pp. 901-916, 2001.

[12] G. Ivey, "A Listening-formulating Model for Psychoanalytic Psychotherapy," Psychotherapy, vol. 37, no. 1, pp. 22-35, 2000.

[13] N. Coltart, Attention. In Slouching Towards Bethlehem: And Further Psychoanalytic Explorations. London: Free Association Books, pp. 176-93, 1992.

[14] T. Reik, Listening with the Third Ear: The Inner Experience of a Psychoanalyst. New York: Farrar, Straus and Company, pp. 144-172, 1948.

[15] W. Bion, Second Thoughts. New York: Jason Aronson, pp. 110-119, 1962. 